\title{
THE USE OF PORTFOLIOS FOR CONTINUING ASSESSMENT OF PHYSIOTHERAPY STUDENTS IN Clinical Practice Settings
}

\begin{abstract}
Many and varied methods of assessment are used to evaluate undergraduate physiotherapy students. Different modes of assessment occur as a result of contrasting educational theories and because the purpose of assessment is variable. In this era of performance assessment related to the students' mastery of the core curriculum, portfolios can enhance the assessment process by revealing a range of skills and understandings. This fits snugly into the physiotherapy curriculum for undergraduate continuous assessment purposes. Portfolio assessment can facilitate more reflection on students' learning, more ownership of learning and more awareness of selfdevelopment. This supports the South African Qualifications Authority's objective for higher education of reflection and life-long learning in our students. This article presents discussion on the use of portfolios in physiotherapy student learning and assessment in clinical practice.
\end{abstract}

KEY WORDS: ASSESSMENT, PORTFOLIO, CONTINUOUS ASSESSMENT, REFLECTION, LIFE-LONG LEARNING.

\section{INTRODUCTION}

A modern definition of assessment states that it should be used to judge the effectiveness of student learning as well as provide guidance and feedback to the learner (Freeman and Lewis, 1998). According to Freeman and Lewis (1998) continuing assessment is defined as multiple assessments that are implemented during a course. This is undertaken for a variety of purposes including learning, certification and quality control (York, 1995). Assessment of learning may be done to motivate students, to provide feedback, to consolidate work done, to diagnose strengths and weaknesses and to establish the level of achievement. Part of the assessment done in the clinical block is continuing assessment based on the growth of the student within the learning environment [specific clinical block] and general performance in all aspects. This often presents as being subjective in the majority of cases [personal experience]. Portfolio presentation enables objectivity in the evaluation of students in that students may be given tasks such as written assessments, preparation of case presentations, research on conditions of patients being treated, evidence of any other readings and/or recordings and journal articles. These activities may be assigned marks according to mutually agreed outcomes. The portfolio would provides evidence of the students' work, not only for objective marking purposes, but also provides a means of evidence to students about their learning and growth.

Gipps (1994) stated that assessment is an important part of education and whenever possible it must be of a type suitable to and used for the enhancement of good quality learning. Assessment should support the teaching and learning of important skills and concepts. In the Physiotherapy programme, this includes both knowledge and practical skills. Michelson (1996) suggested that true assessment should be integrated into the learning process. Portfolio assessment can facilitate students in being more reflective about their learning, taking more ownership of learning and becoming more aware of self-development (Mbali, 1999).

Assessment of students' skills in physiotherapy [whether writing, practical or clinical skills] is important in that it is a reflection of student learning. The tools we use for assessment purposes should reflect the kind of student learning we wish to inculcate in students. It is important that we have adequate assess- ment tools to measure student learning in order to facilitate efficient and effective means of providing physiotherapy interventions. As important, is that students may see evidence of their learning and growth to keep motivated and to strive for continued improvement.

\section{MODES OF ASSESSMENT IN PHYSIOTHERAPY}

These include objective tests, shortanswer questions, exams and tests, extended written work, performance tests, assessment of oral work, class participation, projects, continuing evaluation and problem-solving skills. Assessment can be recorded and reported through logs, diaries, portfolios, video recordings and projects. Characteristics, advantages and disadvantages of these methods are described by a number of authors (Mbali, 1999; Freeman and Lewis, 1998; Nightingale et al, 1996).

\section{CORRESPONDENCE TO:}

Ms Nirmala Naidoo

University of Kwa-Zulu Natal

Physiotherapy Department

Private Bag X54001

Durban 4000

Tel: (031) 260-4817

E-mail: naidooni@ukzn.ac.za 
Clarity of objectives and outcomes, and availability of guidance for students and tutors are some of the factors to be considered when designing or selecting the most appropriate mode of assessment for a given situation.

\section{ASSESSMENT BY PORTFOLIO}

Glen and Hight (1992) defined a portfolio as a file or folder of information which has been accumulated about a student's experiences and accomplishments, a process by which prior experiences can be transmitted into educational outcomes or competencies, documented and assessed for academic credits or recognition. They found the underlying basis for the portfolio as a method of documenting learning in the four assumptions regarding adult learners:

- The student is self-directed

- Past experience is a rich source of learning

- Readiness to learn is developed from tasks and problem-solving

- Students are self-motivated to grow and achieve

A portfolio is a purposeful collection of student work that exhibits the student's efforts, progress and achievements in one or more areas of the curriculum (Paulson et al, 1991). Some examples of what can be included in a portfolio for clinical assessment are described in sections 4 and 5 of this report. According to Kolb (1987), methods of assessment translate into various preferred learning styles and educators should be sensitive to this in the choice of assessment methods. Continuous assessment often misses opportunities for formative feedback and reflection on criteria and experiences. By using portfolio assessment, lecturers can facilitate their students' motivation to learn, their reflection on their learning and more awareness of self-development (Mbali, 1999). Students learn and improve in different ways and at different paces, and it is important to give them opportunities of variety within assessment to get feedback. Assessment by portfolios supports this.

Stephenson and Weil (1992) feel that higher education should give students the confidence and ability to take responsibility for their own continuing personal and professional development and promote the pursuit of excellence in the acquisition, development and application of knowledge and skills. Portfolios would support this and would encourage students to be more integrative (Mbali, 1999). In physiotherapy this implies a wide range of skills, the capacity to select appropriately from these skills, to combine skills, the ability to be a reflective practitioner, adaptability and autonomy (Schon, 1983).

Assessment policy and practice should develop in line with the educational assessment paradigm. There is a paradigm shift towards integrating assessment with learning: continuing assessment, records of achievement, portfolios, practical tasks, as well as the use of results as feedback to help define objectives and encourage learners to take responsibility for their own learning. Basic skills are not enough (Gipps, 1994). The ethics of assessment demand that the constructs and assessment criteria are made available to learners and that a range of tasks and assessments be included in an assessment programme. Assessment by portfolio ties in with these principles.

Although some tertiary institutions training undergraduate physiotherapy students use this form of assessment, there is no published literature to support the use of portfolios in physiotherapy training, especially in the South African context. This would be a particularly interesting and a valuable exercise as the clinical responsibility of students is possibly greater than in other countries. This may also vary in the different universities in South Africa.

It is anticipated that the use of a portfolio would provide the following:

1. Support of validity and reliability criteria, including the inclusion of more than one examiner (Lund, 1995).

2. Assessors can be consistent and objective with this assessment method.

3. The assessors may monitor time management of the students more effectively.

4. Learning achievements and progress may be monitored for individual students.
5. Documentation can be viewed and assessed in toto for evidence of learning.

\section{RELIABILITY AND VALIDITY}

Reliability is defined as the degree to which an assessment yields equivalent results under the same conditions (Nightingale et al, 1996). The authors state that to claim that assessment is reliable measurements must be shown to be consistent over different administrations of the activity or through separate marking by different markers. Set criteria may be drawn up for the marking of the portfolios and markers are to include internal as well as external examiners of the portfolios. An assessment form may be formulated and negotiated with students. Thought needs to be given to tasks included for marks in the portfolio and on those only for the purposes of lifelong learning.

Validity can broadly be defined as the degree to which an assessment assesses what it intended to assess (Nightingale et al, 1996). Portfolios focus on process and learning, and although marking relies on some professional judgement, this process is not altogether subjective (Hagar, 1994).

Freeman and Lewis (1998) provide suggestions for improving reliability and validity. They suggest that reliability of assessment can be improved by:

- creating and using clear criteria to measure student performance

- assessment by a third party

- adjusting marks and double marking

- developing a small number of simple criteria as opposed to a complicated marking scheme.

Validity of assessment can be improved, as suggested by Freeman and Lewis (1998), as follows:

- Creating interesting assessment opportunities

- Assessing important rather than trivial outcomes

- Using appropriate assessment methods

- Assessing what has been covered in the curriculum

All of the above can be done for individual students on a continuing basis for the duration of the time in the clini- 
cal area. In general a preferred method would be to include examiners in this assessment. In support of Lund (1995) the external examiners may not be external to the university, as this would require bringing in examiners from another institution on several occasions during the year to examine students in different clinical blocks. The external examiners may include academic staff not supervising students in that particular clinical area and may also include clinicians from the clinical area where the assessment is being carried out. Provided the implementation is successful, with successful quality assurance of the assessment by portfolio, this may be submitted for consideration for the continuous evaluation of students in the clinical areas. There are presently some physiotherapy training institutions that do use this system, however, it would be of interest to both students as well as academic staff to establish consensus on this system and to pool ideas. It would also be of benefit to determine exactly the implementation and evaluation criteria for the portfolios, and also to assess the value of portfolios as a means of assessing student learning in our environment.

\section{LEARNING OUTCOMES}

Learning outcomes are statements of what is expected a student will be able to do as a result of a learning activity (Novack et al, 1996). Students should be made aware of these criteria for the expected outcomes and for marking a portfolio. The following learning outcomes for clinical practice may be affected by use of assessment by portfolio for continuing evaluation in the clinical area and for inclusion in a portfolio:

1. To assess patients to determine diagnosis, list problems in order of priority, formulate a treatment plan and institute appropriate, safe and effective treatment. Students' written assessments of patients can be included in a portfolio and these can be viewed and reviewed for evidence of progress or improvement. These may also be reviewed by students as a means of feedback and learning.
2. To support autonomous, life-long learning. Students would be encouraged to read current information for inclusions of these in the portfolio, e.g. journal articles, accessing the internet, etc.

3. To enable students to be good practitioners through critical reflection on their own practice, e.g. written assessments and logs. Students could reflect on what they have done or observed and thereby improve on their own initial efforts.

4. To provide learner-centred activities. The student would include in the portfolio activities that they are involved in and activities that they choose to include, e.g. notes on relevant observations, procedures, etc.

5. Experience ownership of portfolio which is conducive to a deep approach to learning (Barnett, 1992). Evidence of the coverage of a minimum number of the suggested readings must be provided. Reactions and reflections on readings with reference to patients treated.

6. Promotes interaction with others as there could be discussion with others [colleagues or members of the multidisciplinary team, etc]. Examples are lectures, discussion groups at the clinical sites, ward rounds, etc. Case studies of patients treated may be included [with references to readings and their sources]. Case conferences with the multidisciplinary team members could also be included.

7. It gives students the experience of formative assessment practice with experiential learning in an authentic environment and would encourage active learning.

\section{ADVANTAGES AND DISADVANTAGES OF PORTFOLIOS}

The advantages of a portfolio would tie in with the learning outcomes. Portfolios may provide a large degree of objectivity in marking, by providing set criteria for marking with evidence being provided by the content of the portfolio. This may not differ from the current system, however it provides the possibility of a particularly good assessment tool to evaluate student learning. Of great importance is the training of both staff and students in the use and marking of the portfolios. The added time and effort required by students to put the portfolio together may be seen as a disadvantage. Students may also lack accuracy in describing their reflections of personal aspects of their work. It may also be seen to be time-consuming to mark the portfolios. However, different modes of learning are incorporated in gathering the portfolio and this would appeal to the variety of learners who present themselves in the physiotherapy programme.

There may certainly be further advantages and disadvantages, especially if these lengthy portfolios are to be read and marked.

\section{CONCLUSION}

Assessment should support the teaching and learning of important skills and concepts (Gipps, 1994). Portfolios may offer a way of assessing student learning that is different from traditional methods (Paulson et al, 1991). It may provide an opportunity for students and evaluators to observe students' development, creating solutions and learning to make judgements on their own performance.

Good quality assessment is to elicit quality performance within a well defined context. It must be scored fairly [in a way the student understands] and consistently [across students and lecturers] in order to move the learners on in an appropriate direction. We need to address the demand for accountability and excellence to monitor students' achievements, growth and progress in order to provide feedback and install the necessary assistance to students who are not meeting the criteria or identified standards.

\section{RECOMMENDATIONS}

According to York (1995) in looking at capabilities in assessment, there are reasons for the weakness of assessment practice. Whilst the physiotherapy programme is consistent with the notion of development of capabilities, the actual assessments that are undertaken give 
broad emphasis towards subject-specific skills [personal experience]. This is a particularly negative aspect of the modular system where students tend to see modules as a package and avoid an integrative and holistic approach.

Assessment by portfolio is best implemented in clinical areas in physiotherapy when used to achieve specific objectives. It is imperative that there is consistency by all assessors and that the requirements are reinforced with the students. In order to enhance the application of portfolios it is important to include all stakeholders (eg. students, staff, potential employers, etc.).

Although this seems to be a plausible method of assessment in physiotherapy, which may already have been implemented at some physiotherapy training institutions, there is need for further research in this area to gain evidence for and insight into the use of this method of assessment, especially with regards to claims of enhancing student learning.

\section{REFERENCES}

Barnett R 1992 Ed. Learning to effect. SRHE \& OUP; Buckingham.

Freeman R, Lewis R 1998 Planning and Implementing assessment. Kogan Page. London.

Gipps C 1994 A framework for Educational Assessment. Chapter 9. Kogan Page. London.

Glen S, Hight NF 1992 Portfolios: An affective assessment strategy? Nurse Education Today $12,416-423$

Hagar P, Gonczi A, Athanasou J 1994 General issues about assessment of competence. Assessment and evaluation in Higher Education. 19 (1): 3-15

Kolb D 1984 Experiential learning: Experience as a source of learning and development. Chapter: Process of Experiential Learning New Jersey. Prentice Hall.

Lund JR 1995 Examinations and assessment. Document presented at the Academic Affairs Board, University of Natal.

Mbali C 1999 Using portfolios to develop reflective higher education practitioners. South African Journal of Higher Education $13: 2$
Michelson E 1996 Multicultural approaches to portfolio development. Assessing adult learning in diverse settings: Different issues and approaches. New York State University Press: $40-53$

Nightingale, Te Waite, Toctey, Ryan, Hughes, Magin 1996 Glossary and Annotated Bibliography. In Assessing learning in universities. University of New South Wales, Sydney.

Novack JR, Ilerman JL, Gearhart M 1996 Issues of portfolio assessment. National Center for Research and Evaluation, Los Angeles.

Paulson PL, Paulson PR, Meyer CA 1991 What makes a portfolio a portfolio? Educational Leadership (3): 60-63

Schon DA 1983 The reflective practitioner: How professionals think in action. In: Part I - From Technical Rationality to Reflectionin-Action. New York. Basic books: 21 - 32

Stephenson J, Weil S (Editors) 1992 Quality in learning. Chapter: A capability approach to Higher Education London. Kogan Page

York M 1995 Assessing capability in degree and diploma programmes. Proceedings of a conference held in Liverpool on 8 February 1995. Liverpool. Centre for Higher Education Development. Liverpool John Moores University.

\section{Patient not feeling as well as a Thomson's Gazelle? Try} REITZER'S IUSCLE $-\ln \mathrm{Gel}$
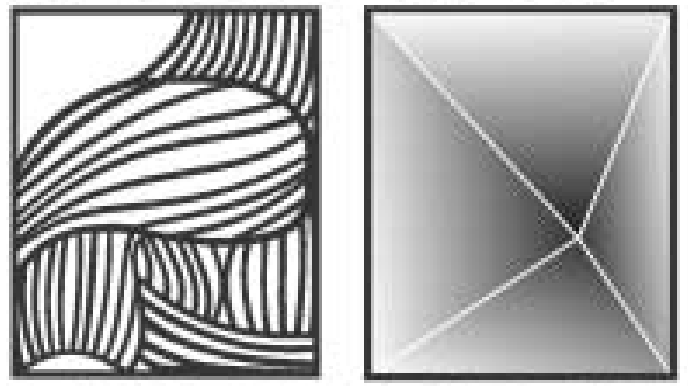

High Concentration Arnica Oil Non-Sticky

Ideal for Massaging

For use with all electronic treatment equipment Reduce the Swell with Muscle-In Gel

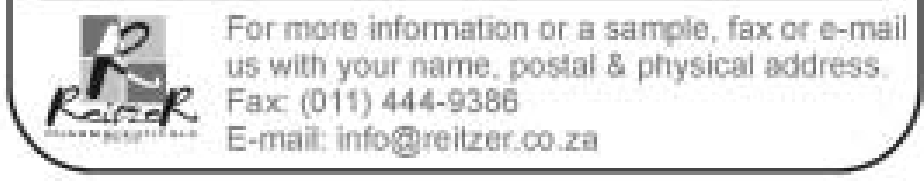

ANSWERS TO QUESTIONS: (Vol 60 No 3)

$\begin{array}{lrll}\text { 1. } & \text { d } & 6 . & \text { b } \\ \text { 2. } & \text { a } & 7 . & \text { a } \\ \text { 3. } & \text { b } & 8 . & \text { a } \\ \text { 4. } & \text { c } & 9 . & \text { b } \\ \text { 5. } & \text { c } & 10 . & \text { d }\end{array}$

\section{How to SUbmit your ANSWERS FOR CPD POINTS:}

1. Complete questionnaire.

2. Ensure that you have included your full details as requested.

3. Only original questionnaires will be considered therefor please cut out and submit to the SASP Head Office at: SASP CPD Questionnaire

P.O. Box 92125 Norwood 2117

4. In order to capture your CPD points at the HPCSA your submission must be accompanied by a cheque/ postal order to the value of $\mathbf{R 2 0 . 0 0}$ (no cash), made out to the South African Society of Physiotherapy. 